\title{
Non-invasive time-lapse imaging of moisture content changes in earth embankments using electrical resistivity tomography (ERT)
}

\author{
J.E. Chambers, D.A. Gunn, P.B. Wilkinson \& R.D. Ogilvy \\ British Geological Survey, Nottingham, UK \\ G.S. Ghataora \& M.P.N. Burrow \\ Department of Civil Engineering, University of Birmingham, Birmingham, UK
}

R. Tilden Smith

Great Central Railway (Nottingham) Limited, Nottingham, UK

\begin{abstract}
Earth structures, such as embankments, require ongoing monitoring and maintenance to identify potential failure zones and to compensate for the effects of settlement. Extreme weather events leading to prolonged periods of desiccation or saturation are becoming more frequent and threaten embankment stability. In this paper the development of electrical resistivity tomography (ERT) as a non-invasive tool for characterizing and monitoring earth embankments is described.

A study is presented in which ERT was applied alongside conventional intrusive techniques to investigate and monitor a section of Victorian era embankment on the Great Central Railway. ERT electrodes were permanently installed as a series of linear 2D arrays, both parallel and perpendicular to the long-axis of the embankment. The resulting ERT images, when calibrated using intrusive sampling methods, revealed the spatial variability of the embankment soils and were used to identify major discontinuities between material types at locations associated with poor track geometry. Subsequently time-lapse ERT images were used to monitor moisture content changes in the embankment; these images revealed both the spatial extent and magnitude of water content variations, and were used to assess the effect of an exceptionally prolonged and heavy period of rainfall during the summer of 2007.
\end{abstract}

\section{ELECTRICAL SURVEY DESIGN}

The test area (Figure 1) covers a $100 \mathrm{~m}$ length of embankment $(y=-20$ to $80 \mathrm{~m})$, which includes the crest and the two flanks ( $x=0$ to $31 \mathrm{~m}$ ). Geotechnical tests (trial pits, boreholes \& cone penetration tests), described by Gunn et al. (2007), were restricted primarily to the crest of embankment ( $x=8$ to $24 \mathrm{~m})$. However, the resistivity images extended the full length and width of the area (Figure 2).

Prior to the field survey, synthetic modelling studies were undertaken to quantify the effects of a conductive metal rail on electrical resistivity tomography (ERT) measurements made along a line running parallel to it for a range of standard ERT electrode configurations (e.g. Dahlin and Zhou, 2004). It was considered that conductive rails could potentially short-circuit the injected current, thereby distorting the resistivity images. These studies revealed that the dipoledipole array configuration was less affected by the

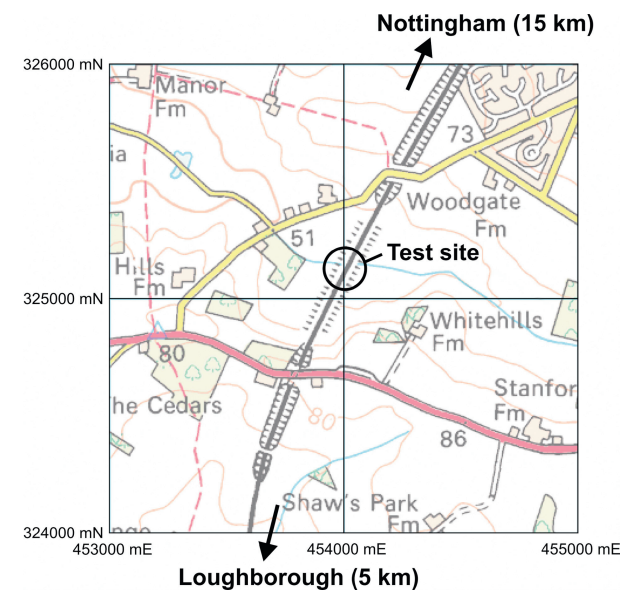

Figure 1. Test site location. Ordnance Survey CCrown copyright. All rights reserved. Licence number $100017897 / 2008$. 


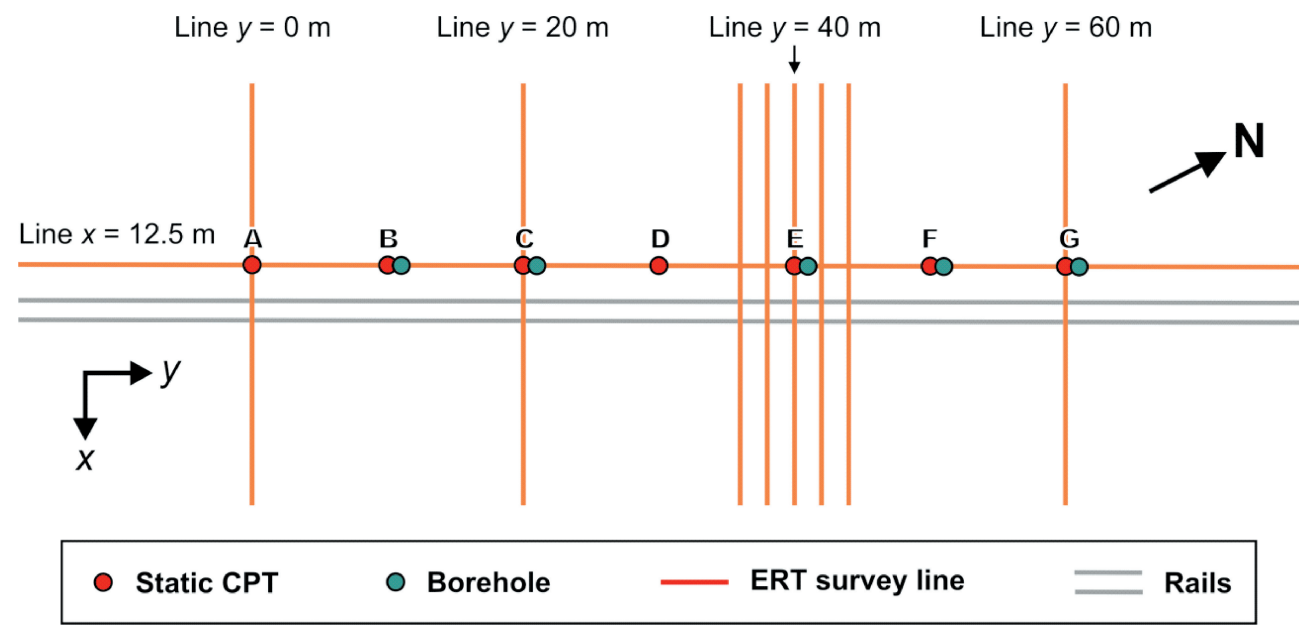

Figure 2. ERT survey line and intrusive sample positions.

(a) NORMAL

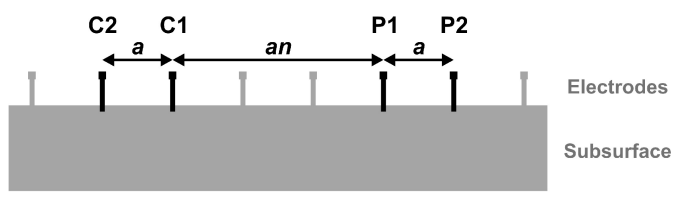

(b) RECIPROCAL

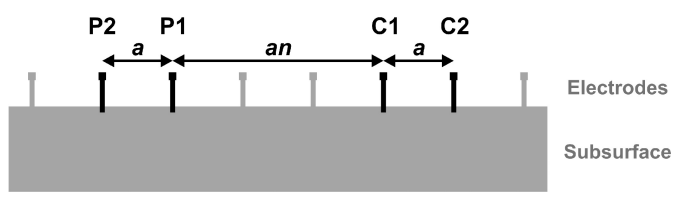

Figure 3. Normal and reciprocal dipole-dipole measurement configurations.

conductive rails than other standard array types; moreover, it was found that given a sufficiently high contact resistance between the rail and the ground, the influence of the conductive rails on the resistivity image would be small; in this case assessment of the field data showed that rail-ground contact resistances were sufficiently high to have effectively eliminated the problem of current short circuiting through the rails.

All resistivity data were collected using the dipoledipole array configuration (Figure 3), and were inverted using Res2DInv software (Loke, 2006) to produce images of the resistivity distribution within the embankment. The dipole-dipole command sequences comprised both normal and a full set of reciprocal measurements. Reciprocal measurements provide a robust means of assessing ERT data quality and determining reliable and quantitative data editing criteria. Data collected parallel to the embankment long-axis $(y)$ used electrode arrays with dipoles $(a)$ of $1.5,3,4.5$ and $6 \mathrm{~m}$, and unit dipole separations $(n)$ of 1 to 8 , whilst measurements collected on the perpendicular sections employed dipoles of $1,2,3$, and $4 \mathrm{~m}$, and unit dipole separations of 1 to 8 . Resistivity images collected during an initial reconnaissance survey of the site during September 2005 are shown in Figure 4.

\section{EMBANKMENT CHARACTERISTICS}

Intrusive investigations within the test area have shown that the embankment is approximately $5.5 \mathrm{~m}$ high, and is underlain by Mercia Mudstone bedrock. The embankment comprises weathered mudstone material between $y=-20$ and $40 \mathrm{~m}$, which was excavated from a nearby cutting and is characterized by relatively low resistivities of less than $100 \Omega \mathrm{m}$ (Figure 4, ERT line $x=12.5 \mathrm{~m}$ ). Beyond $y=40 \mathrm{~m}$ the composition of the embankment changes to gravel, sand and silt, and is characterized by resistivities significantly in excess of $100 \Omega \mathrm{m}$. At the interface between these two distinct lithologies significant distortions in track geometry can be observed, which are likely to be the result of differential settlement. The compositional changes shown in the resistivity section parallel to the embankment long-axis are also seen in the perpendicular sections at $y=0,20,40 \& 60 \mathrm{~m}$ (Figure 4). However, these sections also show significant features associated with variations in moisture content 

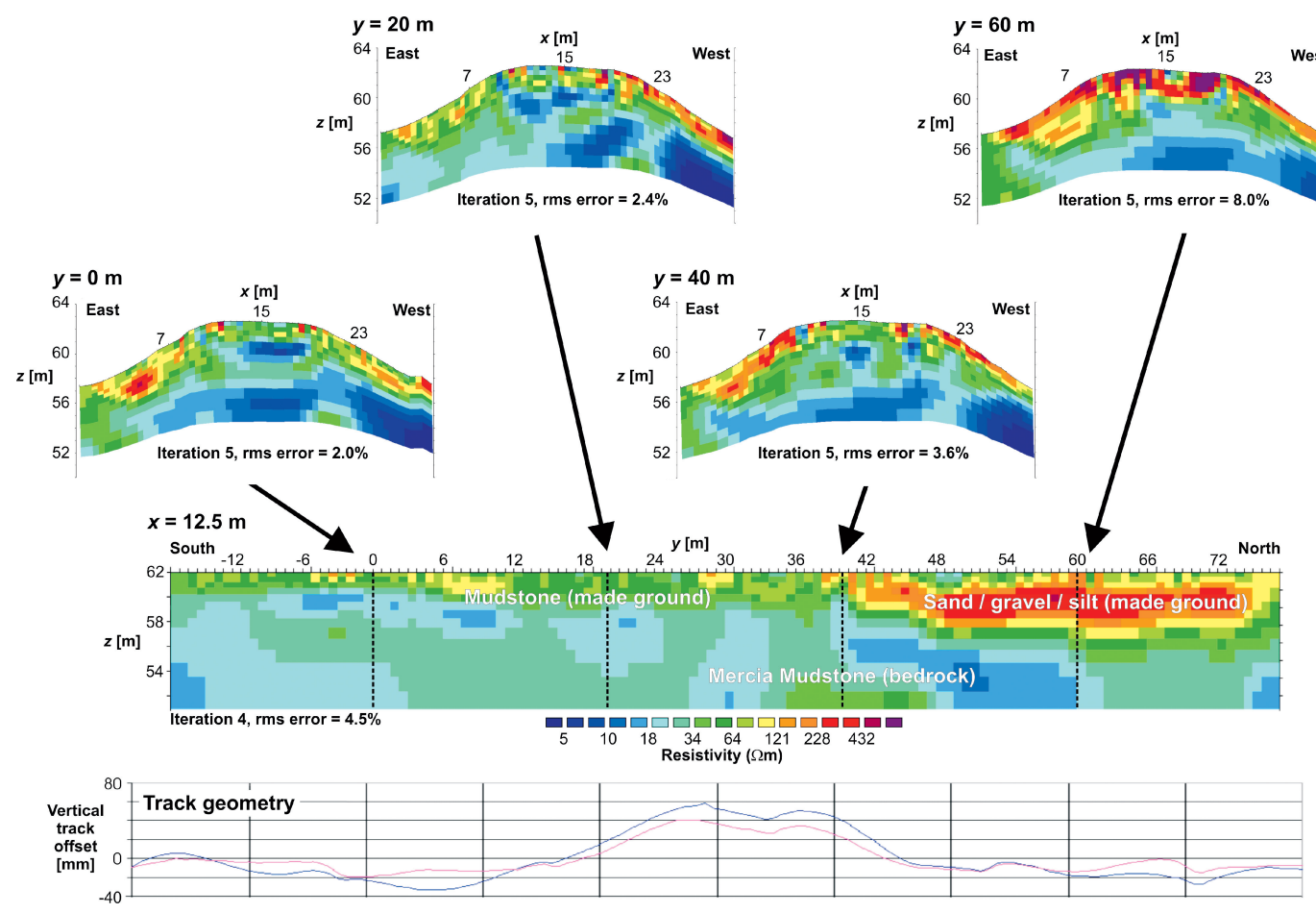

Figure 4. Resistivity models (top) parallel $(\mathrm{x}=12.5 \mathrm{~m})$ and perpendicular $(\mathrm{y}=0,20,40$ and $60 \mathrm{~m})$ to the long axis of the embankment (September 2005). Track geometry profiles (bottom); blue trace - west rail, pink trace - east rail. Track geometry data provided by the Railway Research Centre, University of Birmingham, UK.

within the embankment. In particular, the flanks are dominated by relatively high resistivities due to moisture loss from evaporation and transpiration during the preceding summer months.

\section{SEASONAL MONITORING}

Permanent ERT imaging arrays were installed to better understand the spatial extent and magnitude of moisture content changes within the embankment in the area of poor track geometry. The results from one of these sections, located at $y=40 \mathrm{~m}$ are described here. Datasets have been collected at intervals of approximately 6 weeks in order to monitor seasonal changes. To date, datasets have been collected for the period July 2006 to November 2007. These time-lapse data were inverted using Res2DInv. The July dataset was inverted with a smoothness-constrained ( $\mathrm{L}_{2}$-norm) least-squares method to produce a reference model (Figure 5). Then each of the subsequent datasets was inverted using the July 2006 image as an initial model. A spatial $\mathrm{L}_{2}$-norm constraint was applied to the resistivity differences between the reference model and the model being generated to ensure that these differences

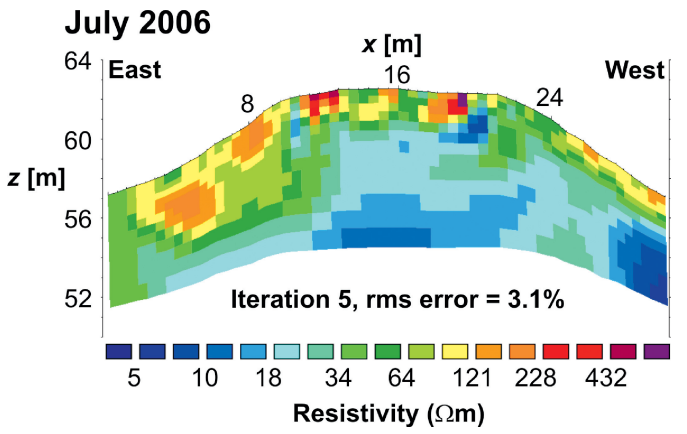

Figure 5. July 2006 ERT reference model at $y=40 \mathrm{~m}$.

varied smoothly with position. This type of crossmodel constraint has been shown to be effective in reducing artefacts that can occur if time-lapse data are inverted independently (Loke, 1999).

The time-lapse resistivity models from August 2006 to November 2007 have been plotted as differential images, which show the percentage change in resistivity relative to the July 2006 reference model; these differential time-lapse resistivity models are shown in Figure 6. This figure shows that drying of the 

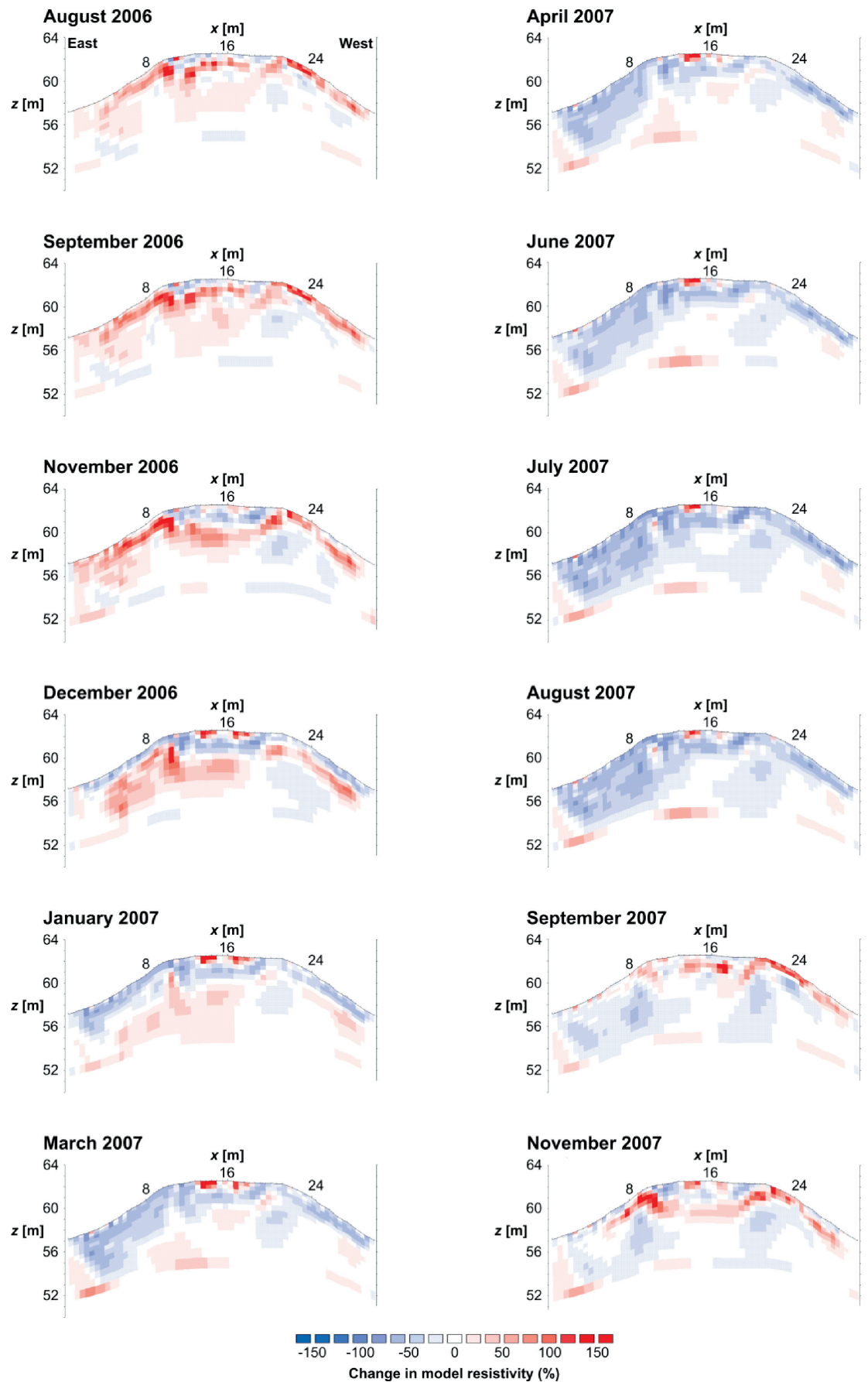

Figure 6. Differential resistivity images at $\mathrm{y}=40 \mathrm{~m}$ showing percentage change in resistivities from the baseline model (July 2006). 


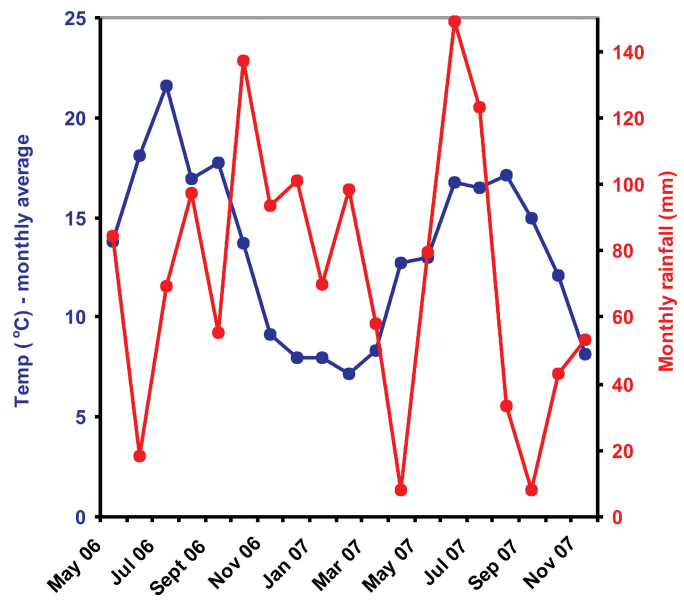

Figure 7. Rainfall and temperature data recorded from a nearby weather station located in Loughborough.

embankment flanks continued until November 2006, after which time resistivities throughout the near surface of the embankment decreased. By March 2007 elevated moisture levels, as identified by decreases in resistivity, are shown to extend to more than $4 \mathrm{~m}$ below ground level. Greater infiltration of moisture appears to have occurred on the eastern flank, from $x=0$ to $10 \mathrm{~m}$, than is seen on the western flank; this may be a function of the prevailing wind direction resulting in uneven evaporation across the embankment, or differences in the density and type of vegetation on the two flanks. The general decrease seen in near surface resistivities over the winter months does not appear to be a function of increased rainfall, which is relatively consistent over the monitoring period (Figure 7). Instead it is likely to be primarily due to decreased vegetation cover and lower temperatures during the winter, which reduced evaporative loss of moisture from the embankment allowing water to penetrate deeper into the subsurface.

Between March and August 2007 the embankment continued to become wetter despite increasing temperature and evapotranspiration. The cause was the extraordinarily high rainfall in June, July and August (Figure 7). The effect of the wet summer on the moisture distribution in the embankment can be seen clearly by comparing the August 2006 timelapse image with that from August 2007. The climatic conditions leading up to August 2006 were far more typical of what would normally be expect during the summer months, and hence the embankment was significantly drier than at the same point in 2007.

The period between September and November 2007 was characterized by much lower rainfall than the preceding months. Consequently, the embankment begins drying, with resistive zones appearing on the crest and flanks of the embankment during September to November.

\section{CONCLUSIONS AND FUTURE WORK}

A study is described in which 2D track-parallel ERT has been used to identify significant compositional variations associated with embankment instability. Further work is required to prove the technique at other sites, and to model and assess the effects of topography on ERT images generated from measurements collected parallel to the long axes of embankments.

Qualitative seasonal changes in embankment moisture content have been monitored using 2D ERT. The monitoring period has included the heavy rainfall that occurred from June to August 2007, which prevented the embankment from drying out over the summer. Monitoring will continue for at least an additional 10 -month period to allow the collection of data over two entire yearly cycles. Additional ERT monitoring arrays have recently been installed at other locations within the test area to study the response of different embankment materials (e.g. gravel, sand and silt) to drying and wetting cycles. Direct in-situ and laboratory-based moisture content and resistivity measurements of embankment materials will be carried out to calibrate the resistivity models and to move towards a quantitative assessment of moisture content changes using ERT data.

The investigation of the relationship between moisture content and the instability of the embankment is a key element of our ongoing research; in particular the shrink/swell effects associated with clay minerals, the mobilization and precipitation of soluble constituents, and changes in strength caused by varying water content are being considered.

Given its low cost and relative rapidity compared to many intrusive methods, ERT may be suitable as a reconnaissance and monitoring tool for identifying potential areas of instability in old earth structures.

\section{ACKNOWLEDGEMENTS}

This paper is published with the permission of the Executive Director of the British Geological Survey (NERC).

\section{REFERENCES}

Dahlin, T., and Zhou, B. 2004. A numerical comparison of 2D resistivity imaging with 10 electrode arrays. Geophysical Prospecting 52: 379-398.

Gunn, D.A., Reeves, H., Chambers, J.E., Pearson S.G., Haslam, E., Raines, M., Tragheim, D., Ghataora, G.S., Burrow, M.P.N., Weston, P., Thomas, A., Nelder, L.M., 
Lovell J.M. \& Tilden Smith, R. 2007. Assessment of embankment condition using combined geophysical and geotechnical surveys. Proc. 9th International Con. Railway Engineering, University of Westminster, London, 20-21 June.

Jackson, P.D., Northmore, K.J., Meldrum, P.I., Gunn, D.A., Hallam, J.R., Wambura, J., Wangusi, B., and Ogutu, G. 2002. Non-invasive moisture monitoring within an earth embankment - a precursor to failure. $N D T \& E$ International 35: 107-115.
Loke, M.H. 2006. RES2DINV Rapid 2-D resistivity and IP inversion using the least-squares method. Manual, Geotomo Software, Penang, Malaysia.

Loke, M.H., 1999. Time-lapse resistivity imaging inversion. 5th Meeting of the Environmental and Engineering Geophysical Society European Section Proceedings. Em1.

Sjodahl, P., Dahlin, T. and Zhou, B. 2006. 2.5D resistivity modeling of embankment dams to assess influence from geometry and material properties. Geophysics 71: G107G114. 